mais atormentam o doente, como a cephaléa, tornando-lhes a vida mais toleravel.

\title{
TRATAMENTO
}

Foi tentado o tratamento especifico pelas injecções de sáes mercuriaes insoluveis e de iodeto de sodio. Poderia ser experimentada a craniectomia descompressiva, tentando-se tambem fazer a extirᄁação do tumor. Entendo, porem, que os effeitos descompressivos talvez possam ser obtidos só pelas punç̧õess rachidianas repetidas. E. é o que vamos fazer.

Quanto á intervenção cirurgica extirpadora, não só o doente não se sujeita a esse tratamento, como, á vista das melhoras verificadas, acho de bom aviso tentarmos por mais tempo o tratamento mercurial, de cuja acção bemfazeja algo podemos esperar.

\section{Um caso de epilepsia Bravais-Jacksoniana}

\author{
POR \\ JOAQUIM PENNINO \\ DOUTORANDO EM MEDICINA
}

No dia 20 de maio p. p. deu entrada em nossa enfermaria um doente recommendado ao Prof. Rubião Meira pelo Dr. Luciano Gualberto. Trata-se do Sr. A. Marcello, com 22 annos de edade, brasileiro, solteiro, sapateiro residente em 's. Paulo.

Diz elle que o pae morreu de uma quéda a grande altura; a mãe está viva e gosa saude. Tem um irmão forte. Não se lembra de ter tido molestias proprias da infancia. Levou um tombo em creança $\theta$ em seguida, aos 2 annos, teve um ataque, segundo lhe diz a propria mãe. Depois disso lembra-se que só aos sete annos reappareceu o ataque, repetindo-se de 15 em 15 dias, mez em mez, e até 2 em 2 mezes. Aos 13 annos, depois de um desastre de automovel em que se lembra só ter fracturado o $1 \mid 3$ inferior do femur esquerdo, notou que os ataques se repetem com muita frequencia durante um certo tempo e como que desapparecem durante um periodo não muito longo.

Após uma pausa de 3 mezes os ataques se repetem todos că ãias com uma frequencia de 6 a 10 por dia.

Symptomatologia. 
No mesmo dia da entrada no Hospital teve um accesso que foi apreciado por alguns collegas.

Sentiu um calor pelo corpo, dôr muito ligeira no braço e na perna direitos. Não soltou grito. os dedos da mão direita se flexionaram sobre o antebraço, este sobre o braço e o membro superior todo nessa situação encostou-se fortemente ao thorax. Desviou a cabeça e os olhos para a direita. Depois desses phenomenos de contractura que duraram muito pouco o membro superior foi tomado de pequenas e rapidas oscillações, com aspecto de convulsões clonicas da epilepsia e que duraram mais ou menos 5 minutos. Pouco a pouco diminuiram de intensidade e foram substituidas por contracções fibrillares a que se seguiram movimentos convulsivos da cabeça. A commissura labial foi repuxada para o lado direito. A perna do mesmo lado agitou-se em extensão devido á propagação das contracções, nunca chegando a se flexionar. Mordeu a lingua, que por sua vez era animada de contracções. Não perdeu a consciencia e assistiu ao ataque, pretendendo com a mão esquerda oppôr-se ás contracções iniciadas nos dedos e estendel-os. Algumas vezes, terminando o ataque sente uma ligeira somnolencia e no inicio urina um pouco. O territorio attingido por esta epilepsia parcial está ligeiramente paresiado. Não tem aphasia, mas a palavra é um pouco difficultada, embaraçada, ha uma paraphasia..

Reflexos augmentados do lado direito.

A's vezes tem ancia de vomito, mas não chega a vomitar.

O braço direito perdeu a força que tinha.

Tem febre ligeira algumas vezes.

Estamos, portanto, deante de um caso de epilepsia parcial ou melhor epilepsia Bravais-Jacksoniana.

O diagnostico está feito mas para ser completo é necessario ser tambem topographico e pathogenico, fazendo antes um ligeiro estudo sobre a epilepsia Jacksoniana e suas variedades.

A epilepsia Jacksoniana nada mais é do que uma epilepsia parcial, caracterisada por accessos convulsivos limitados a um grupo de musculos. Bravais que foi o primeiro a estudal-a admittiu a existencia de 3 variedades: brachial, começando no braço, facial, na cabeça e crural, na perna. No tyno brachial, o mais commum, as diversas partes do membro superior se flexionam umas sobre as outras pela contracção dos flexores e a essa phase de convulsão tonica se succede a dos movimentos convulsivos. No typo facial a cabeça e os olhos são desviados para o lado que se contrae e as convulsões da face e do pescoço attingem a commissura labial, o orbicular das palpebras, os musculos motores do olho, da lingua e o sterno-cleido-mastoideu, como no nosso caso. No typo crural os movimentos convulsivos começam no grande artelho e tomam o membro inferior todo. 
Os accessos de epilepsia começam sempre pela região do corpo correspondente á região do cortex cerebral onde está localisada a lesão.

As convulsões iniciadas numa dada região pódem se propagar a outras subsequentes e, ás vezes, até ao lado opposto, resultando d'isso typos mixtos, como no nosso doente em que ellas começam nos dedos, passam ao membro superior todo $\theta$ depois á cabeça, constituindo o typo brachio-cervico-facial.

O inicio do ataque não é sempre o mesmo: a aura, o grito, a perda de consciencia pódem faltar ou não.

o nosso doente, por exemplo, não grita, não perde a consciencia, ao contrario da epilepsia essencial, mas sente um "calor" pelo corpo antes de ter o accesso.

A duração vae de alguns minutos até uma hora em alguns casos, sendo de 5 minutos no nosso doente.

A frequencia com que se repetem os ataques é muito variavel, como se vê pelo que dissemos acima do nosso caso, 6 a 10 e até mais num dia e durante algumas semanas, havendo uma pausa de 2 e 3 mezes.

Quando os ataques são muito frequentes ha uma elevação forte de tempertura, como diz tel-a algumas vezes o nosso enfermo e o individuo póde até morrer em estado de mal Jacksoniano, como morre de mal epileptico, verificado por Dieulafoy.

As regiões convulsionadas durante 0 accesso conservam depois d'elle um estado paretico, que póde ir até a paralysia completa.

Localisação. Os accessos Jacksonianos têem como ponto de partida uma lesão assestada na zona cortical motora do cerebro, comprehendendo as circumvoluções frontal ascendente e parietal ascendente separadas pelas sisura de Rolando. Essa zona póde ser dividida em 3 regiões secundarias, formando os 3 centros motores principaes, da face e lingua, do braço e da perna, como se vê na figura.

Lesões circumscriptas a cada uma destas porções pódem acarretar symptomas tambem circumscriptos ao braço, perna ou face. Segundo o gráo de destruição ou de irritação do territorio lesado os symptomas pódem ser de paralysia, contractura ou emfim de accessos de epilepsia Jacksoniana.

Quando os accessos começam pela perna a lesão attinge tambem o lobo paracentral, continuação do centro do membro inferior, externo, para a face interna do cerebro, mas nada tem a vêr com elle o nosso caso.

Trata-se, portanto, de uma lesão nos 2 centros inferiores, face e lingua e do membro superior.

Qual é essa lesão?

Uma placa de meningite tuberculosa? Não, porque ella é mals 
commum nos adultos, e no nosso doente a epilepsia começou na infancia, $\Theta$ porque elle não apresenta symptomas de meningite tuberculosa.

Uma lesão syphilitica ?

Não, porque elle nunca teve syphilis e o tratamento mercurial feito por algum tempo em nada aproveitou ao doente.

Será um tumor da cortex ?

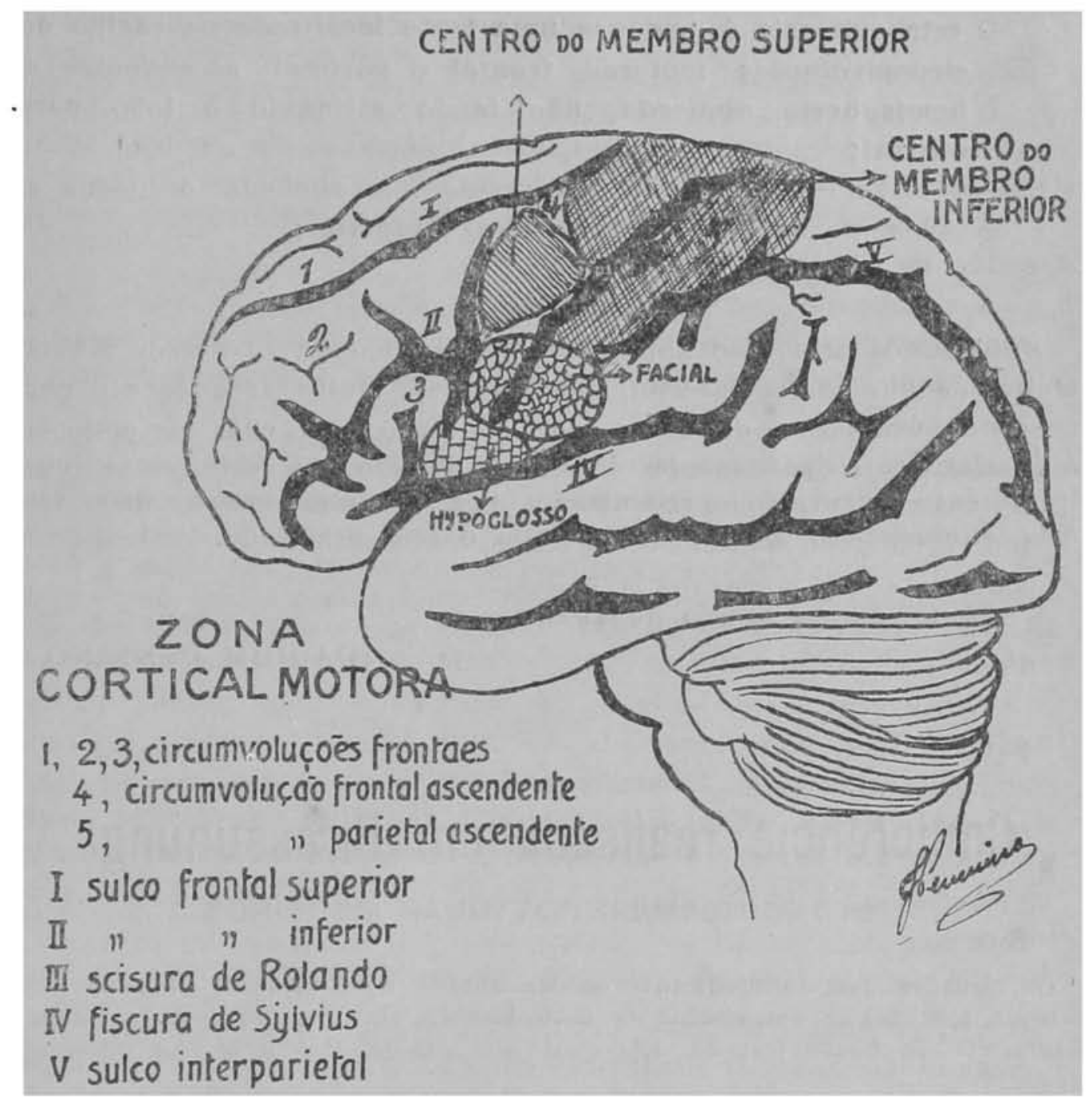

Não, porque elle não apresenta nenhum symptoma proprio dos tumores cerebraes: dôr de cabeça, vomito, stase papillar, hypertensão cephalorachidiana, etc.

Será um traumatismo craneano?

Sim, porque elle conta ter levado um tombo em creanca e desde esse tempo é que tem accessos; -sim, porque elle apresenta, á inspecção, na zona fronto-parietal esquerda uma depressão consideravel. 
Tratamento : intervenção cirurgica.

A intervenção não foi praticada porque o doente ao seber que ia ser operado pediu licença para consultar a familia, sahiu e nunca mais voltou.

Concluimos esta observação dizendo que :

$10^{\circ}$ - o nosso doente é portador de uma epilepsia parcial, Bravais-Jacksoniana, typo brachio-cervico-facial;

2.c - esta epilepsia é devida a uma lesão localisada na região das circumvoluções motoras frontal e parietal ascendentes do hemispherio esquerdo, não tendo attingido o lobo paracentral;

$3 .^{\circ}$ - a lesão consiste numa depressão da aboboda craneana situada na região fronto-parietal esquerda;

$4 .^{\circ}$ - a therapeutica é cirurgica.

Publicamos este caso apparecido no serviço do Professor Rubião Meira, de que somos interno, por não ser muito frequente e para frisar a localisação da lesão em contraposição com a epilepsia essencial, cuja pathogenia é ainda objecto de estudos e cujo tratamento cirurgico preconisado por Championniére não tem conseguido senão dissabores aos que o tem praticado.

S. Paulo, 28 de agosto de 1920 .

JOAQUIM PENNINO

\section{Conferencia realisada em Pirassununga} PELO DOUTORANDO POTYGUAR MEDEIROS

Os doutorandos de medicina, da Faculdade de S. Paulo, gulados pela Missão Ro'kfeller empenham-se actualmente em uma campanha de saneamento do nosso Estaido. Eis como eu vos explico a minha presença entre vos.

Pelas principaes cidades paulistas, por toda's quantas representem nucleos de irradiação de progresso para outras menores, principalmente naquellas onde houver Escolas Normaes para preparo de professores far-se-á ouvir, quando ainda se não houver feito, a voz dos estudantes da sciencia abençoada.

Contamos, os meus distincto's de lucta e eu, que dupla resultante se seguirá ao nosso gesto; primeiro, um resultado immediato, symibolisado pela consideração que fôr tributada aos nossos conselhos por parte dos poderes publicos, das aggremiaçoses escolares e até directamente, sem a interferencia destes seus representantes, pelas populações cidadans e ruraes: resultará ao depois, esperamos, a reproducção do nosso esforço por outras pessoas de outros Estados da União, visando, como 